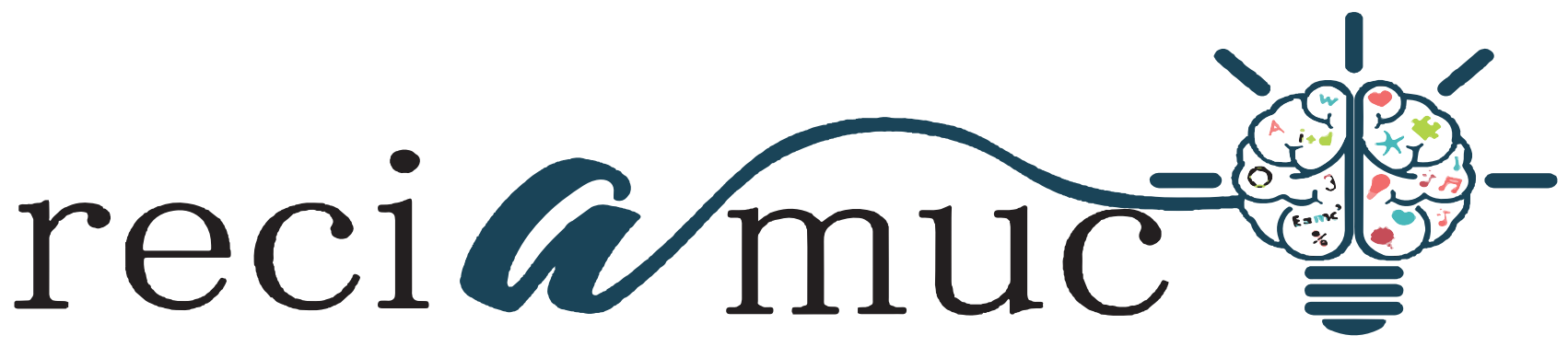

DOI: $10.26820 /$ reciamuc/4.(4).diciembre.2020.102-112

URL: https://reciamuc.com/index.php/RECIAMUC/article/view/573

EDITORIAL: Saberes del Conocimiento

REVISTA: RECIAMUC

ISSN: 2588-0748

TIPO DE INVESTIGACIÓN: Artículo de Revisión

Código UNESCO: 32 Ciencias Médicas; 3201 Ciencias Clínicas

PAGINAS: $102-112$

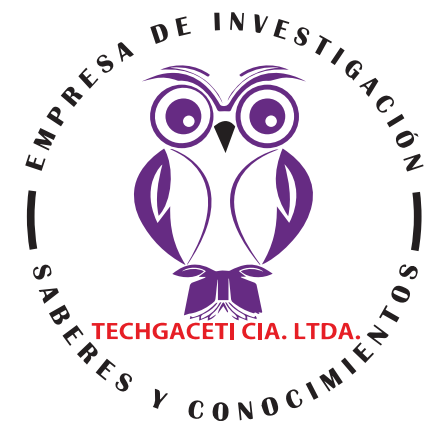

\title{
Inmunoterapia en hemopatías malignas
}

Immunotherapy in malignant hemopathies

Imunoterapia em hemopatias malignas

\section{Andrea Johanna Carvajal Correa'; Danny Israel Gavilema Tipantuña2; Ángel David Pinos Ramírez;; Geomara Jacqueline Curicho Córdova ${ }^{4}$}

RECIBIDO: 23/09/2020 ACEPTADO: 17/10/2020 PUBLICADO: 24/12/2020

1. Médica de la Universidad Central del Ecuador; Quito, Ecuador; andre21carvajal@gmail.com; https://orcid. org/0000-0001-8566-8293

2. Médico de la Universidad Central del Ecuador; Ministerio de Salud Pública de Ecuador: Machachi; Quito, Ecuador; gdannyisrael@gmail.com; https://orcid.org/0000-0001-5626-8987

3. Médico General de la Universidad Nacional de Chimborazo; Riobamba, Ecuador; david.pinos10@hotmail. com; https://orcid.org/0000-0002-6475-2020

4. Médica de la Universidad Central del Ecuador; Quito, Ecuador; geomaracuricho@hotmail.com; https://orcid. org/0000-0002-4206-4809

\section{CORRESPONDENCIA}

Andrea Johanna Carvajal Correa

andre21carvajal@gmail.com

$$
\text { Quito, Ecuador }
$$

○ RECIAMUC; Editorial Saberes del Conocimiento, 2020 


\section{RESUMEN}

El campo de la inmunoterapia en el tratamiento del cáncer se ha acelerado en los últimos años y ha entrado en primer plano como un área líder de investigaciones en curso y terapias prometedoras cambiando el panorama del tratamiento para una variedad de tipos de cáncer. Anteriormente, la inmunoterapia en el tratamiento de neoplasias malignas hematológicas. Sin embargo, hoy en día, este tipo de terapias biológicas es utilizada para estimular las defensas naturales del cuerpo en aras de combatir el cáncer a través de sustancias que produce el mismo cuerpo o que se procesan en laboratorios para mejorar o restaurar el sistema inmunológico del paciente, actuando en el retraso del crecimiento de las células cancerígenas, impidiendo la diseminación hacia otros órganos y ayudando al sistema inmunitario a la hora de destruir las células malignas. En el siguiente proceso investigativo se enmarca una revisión de varias formas de terapias basadas en el sistema inmunológico, que han demostrado ser muy prometedoras en pacientes con neoplasias hematológicas, incluidas las terapias monoclonales convencionales como rituximab; anticuerpos monoclonales diseñados mediante ingeniería denominados engagers de células T biespecíficas; anticuerpos monoclonales y fármacos que bloquean las vías inhibidoras de las células T (es decir, PD-1, CTLA-4 e IDO); terapia de transferencia celular adoptiva con células T diseñadas para expresar receptores de antígenos quiméricos o receptores de células T. También se evalúa la idea de usar estas terapias en combinación sugiriendo enfoques de múltiples puntas para mejorar los resultados del tratamiento y las respuestas curativas en los pacientes.

Palabras clave: Inmunoterapia, neoplasias hematológicas, trasplante de células madre.

\section{ABSTRACT}

The field of immunotherapy in cancer treatment has acceler-ated in recent years and has come to the fore as a leading area of ongoing research and promising therapies changing the treatment landscape for a variety of cancers. Previously, immunotherapy in the treatment of hematologic malignancies. However, today, this type of biological therapy is used to stimulate the body's natural defenses in order to fight cancer through substances that the body itself produces or that are processed in laboratories to improve or restore the immune system of the body. patient, acting to delay the growth of cancer cells, preventing their spread to other organs and helping the immune system to destroy malignant cells. The following research process is part of a review of various forms of therapies based on the immune system, which have shown great promise in patients with hematological malignancies, including conventional monoclonal therapies such as rituximab; engineered monoclonal antibodies called bispecific T cell engagers; monoclonal antibodies and drugs that block T cell inhibitory pathways (ie, PD-1, CTLA-4, and IDO); Adoptive cell transfer therapy with T cells engineered to express chimeric antigen receptors or T cell receptors. The idea of using these therapies in combination is also being evaluated suggesting multi-pronged approaches to improve treatment outcomes and curative responses in patients.

Keywords: Immunotherapy, hematologic malignancies, stem cell transplantation.

\section{RESUMO}

O campo da imunoterapia no tratamento do cancro acelerou nos últimos anos e tem vindo a assumir uma posição de liderança como uma área de investigação em curso e terapias promissoras que alteram o panorama do tratamento de uma variedade de cancros. Anteriormente, a imunoterapia no tratamento de malignidades hematológicas. Contudo, hoje em dia, este tipo de terapia biológica é utilizado para estimular as defesas naturais do organismo a fim de combater 0 cancro através de substâncias que o próprio organismo produz ou que são processadas em laboratórios para melhorar ou restaurar o sistema imunitário do organismo. paciente, actuando para retardar o crescimento de células cancerosas, impedindo a sua propagação a outros órgãos e ajudando o sistema imunitário a destruir as células malignas. O processo de investigação seguinte faz parte de uma revisão de várias formas de terapias baseadas no sistema imunitário, que demonstraram grande promessa em doentes com malignidades hematológicas, incluindo terapias monoclonais convencionais, tais como rituximab; anticorpos monoclonais engendrados chamados engagers de células T bi-específicas; anticorpos monoclonais e medicamentos que bloqueiam as vias inibitórias das células T (ou seja, PD-1, CTLA-4, e IDO); terapia de transferência de células adoptivas com células T engendradas para expressar receptores de antigénios quiméricos ou receptores de células T. A ideia de utilizar estas terapias em combinação também está a ser avaliada, sugerindo abordagens multi-facetadas para melhorar os resultados do tratamento e as respostas curativas nos pacientes.

Palavras-chave: Imunoterapia, malignidades hematológicas, transplante de células estaminais. 
VA, G. J.

\section{Introducción}

Si bien es cierto, el cáncer es un tipo de enfermedad que genera altas tasas de mortalidad a nivel mundial, la inmunoterapia ha servido como tratamiento de vanguardia y líder en el desarrollo de investigaciones y terapias que brindan un panorama muy asertivo, solido y natural que ofrece una visión amplia del potencial que promete la inmunoterapia en neoplasias hematológicas.

Aquellos en el campo del tratamiento de neoplasias hematológicas pueden presumir de utilizar una de las formas más antiguas de inmunoterapia contra el cáncer, el trasplante alogénico de células madre hematopoyéticas (HCT). El primer trasplante alogénico "fue realizado en 1968 por E. Donnall Thomas, quien llegaría a ganar el Premio Nobel por ser pionero en esta tecnología y padre del trasplante de células madre, aunque se le ha referido como el arma más contundente del quimioterapeuta" (Mukherjee, 2010), ya que de hecho tiene como objetivo erradicar los sistemas hematopoyético e inmunológico de un paciente, a menudo es la única opción curativa para muchos pacientes con neoplasias hematológicas.

Con la ampliación de las indicaciones clínicas y el uso de donantes alternativos, su uso solo continúa aumentando. Además, el HCT alogénico ha proporcionado un modelo de inmunoterapia en neoplasias malignas hematológicas, ofreciendo información invaluable que se puede utilizar a medida que el campo avanza. Las autoras (Caballeros, López, \& Cabrero, 2012) exponen que por ejemplo, "se ha aprendido acerca de la sensibilidad de las neoplasias malignas hematológicas al efecto injerto contra leucemia o injerto contra tumor y, por lo tanto, se sabe que estos son objetivos apropiados para la inmunoterapia".

De acuerdo con Caballeros, López, \& Cabrero, (2012), ésta sensibilidad ha sido demostrado por varios factores:

1. La eficacia del alotrasplante en la enfer- medad quimio refractaria.

2. El uso de infusiones de linfocitos de donantes para tratar la recaída después del trasplante.

3. El uso de regímenes de acondicionamiento de intensidad reducida o no mieloablativos ("minitrasplante"), en los que la eficacia y la erradicación de la enfermedad se basan principalmente en el efecto injerto contra leucemia, con poca contribución de dosis de quimioterapia.

La supervivencia general después del trasplante alogénico ha mejorado significativamente durante las últimas décadas, "aunque esto se debe principalmente a las mejoras en la mortalidad sin recaídas y los avances en la atención de apoyo (tratamiento y prevención de infecciones o enfermedad de injerto contra huésped (GVHD), por ejemplo)" (Chang, Xu, \& Wang, 2016). Además, se han perfeccionado nuevas estrategias de trasplante para superar obstáculos como la disponibilidad de donantes. "Por ejemplo, el trasplante de donante haploidéntico que utiliza ciclofosfamida postrasplante como profilaxis de la EICH ha mostrado resultados similares a los trasplantes de donantes no emparentados compatibles con menor riesgo de EICH" (Chang, Xu, \& Wang, 2016).

Este tipo de estrategias han ampliado la aplicabilidad del trasplante alogénico y tendrán un impacto en el campo del trasplante en el futuro. Desafortunadamente, la recaída de la neoplasia maligna subyacente sigue siendo la causa más común de fracaso o muerte después del trasplante, lo que subraya la necesidad de mejorar la forma en que podemos aprovechar el sistema inmunológico para tratar las neoplasias malignas hematológicas y hasta dónde se debe llegar para lograr la curación. No obstante, se ha aprendido muchísimo sobre el sistema inmunológico en el tratamiento de neoplasias malignas hematológicas y su evolución, así como también, en el avance del TCH alogénico, ayudando en el progreso del campo de nuevas inmunoterapias. 
Aunque la inmunoterapia ha mostrado éxito en una amplia variedad de cánceres, incluidos muchos tumores sólidos, existen algunas características únicas de las neoplasias hematológicas en este contexto que hacen que estos cánceres estén bien posicionados como objetivos de la inmunoterapia. Primero está la sensibilidad al ataque inmunológico.

Las células del sistema inmunológico y las células malignas están en contacto constante entre sí dentro del sistema hematopoyético, lo que hace que el entorno sea propicio para la vigilancia inmunitaria constante. Además, dado que los orígenes celulares de la malignidad son los del sistema inmunológico, estas células malignas son inmunoestimuladoras por naturaleza. (Caballeros, López, \& Cabrero, 2012)

En contraste con estas ventajas, también existen algunas desventajas que las neoplasias hematológicas conllevan en este contexto, relacionadas con estos mismos factores. Como se mencionó, "los orígenes celulares son los mismos entre la malignidad y el sistema inmunológico. Esto de alguna manera es ventajoso, la desventaja es que las propias células malignas también pueden ser estimuladas por la respuesta inflamatoria y el medio de citocinas" (Chang, Xu, \& Wang, 2016). Además, "dado que estas células son por su propia naturaleza explotaciones del sistema inmunológico normal, se sabe que la respuesta inmunitaria normal es deficitaria y puede verse obstaculizada en general" (Whiteside, 1998). Por último, y lo que es más importante, los mecanismos mediante los cuales las neoplasias han logrado la evasión inmunitaria son probablemente excepcionales, dado el estrecho contacto con las células inmunitarias normales. Por lo tanto, las estrategias inmunes exitosas deben poder superar estos mecanismos de escape inmunológico.

Esta revisión se centrará en cinco categorías de inmunoterapias en el tratamiento de neoplasias hematológicas en las que se ha acelerado el desarrollo, sobre la base de diversas estrategias para aprovechar el sistema inmunológico. Cabe señalar que existe investigación y desarrollo en curso de otras estrategias novedosas que pueden estar ingresando al campo clínico en un futuro próximo.

\section{Metodología}

Para el desarrollo de este proceso investigativo, se plantea como metodología la encaminada hacia una orientación científica particular que se encuentra determinada por la necesidad de indagar en forma precisa y coherente una situación, en tal sentido Davila, (2015) define la metodología "como aquellos pasos anteriores que son seleccionados por el investigador para lograr resultados favorables que le ayuden a plantear nuevas ideas" (p.66)

Lo citado por el autor, lleva a entender que el desarrollo de la acción investigativa busca simplemente coordinar acciones enmarcadas en una revisión bibliográfica con el fin de complementar ideas previas relacionadas Inmunoterapia en hemopatías malignas a través de una revisión de literatura, para así finalmente elaborar un cuerpo de consideraciones generales que ayuden a ampliar el interés propuesto.

\section{Tipo de Investigación}

Dentro de toda práctica investigativa, se precisan acciones de carácter metodológico mediante las cuales se logra conocer y proyectar los eventos posibles que la determinan. En este sentido, la presente investigación corresponde al tipo documental, definido por Castro (2016), "se ocupa del estudio de problemas planteados a nivel teórico, la información requerida para abordarlos se encuentra básicamente en materiales impresos, audiovisuales y / o electrónicos". (p.41).

En consideración a esta definición, la orientación metodológica incluye la oportunidad de cumplir con una serie de actividades in- 
VA, G. J.

herentes a la revisión y lectura de diversos documentos, donde se encuentran ideas explicitas relacionadas con los tópicos encargados de identificar una característica inmersa en el estudio. Por lo tanto, se realizaron continuas interpretaciones con el claro propósito de revisar aquellas apreciaciones propuestas por diferentes investigadores en relación al tema de interés, para luego dar la respectiva argumentación a los planteamientos, en función a las necesidades encontradas en la investigación, apoyados en las herramientas tecnológicas para la búsqueda de trabajos con valor científico disponibles en la web que tenían conexión con el objetivo principal de la investigación.

\section{Fuentes Documentales}

El análisis correspondiente a las características que predomina en el tema seleccionado, llevan a incluir diferentes fuentes documentales encargadas de darle el respectivo valor científico y en ese sentido cumplir con la valoración de los hechos a fin de generar nuevos criterios que sirven de referencia a otros procesos investigativos. Para Castro,(2016) las fuentes documentales incorporadas en la investigación documental o bibliográfica, "representa la suma de materiales sistemáticos que son revisados en forma rigurosa y profunda para llegar a un análisis del fenómeno" (p.41). Por lo tanto, se procedió a cumplir con la lectura previa determinada para encontrar aquellos aspectos estrechamente vinculados con el tema, con el fin de explicar mediante un desarrollo las respectivas apreciaciones generales de importancia.

\section{Técnicas para la Recolección de la Infor- mación}

La conducción de la investigación para ser realizada en función a las particularidades que determinan a los estudios documentales, tiene como fin el desarrollo de un conjunto de acciones encargadas de llevar a la selección de técnicas estrechamente vinculadas con las características del estudio. Bolívar, (2015), refiere, que es "una técnica particular para aportar ayuda a los procedimientos de selección de las ideas primarias y secundarias". (p.71).

Tal como lo expresa, Bolívar, (2015) "Las técnicas documentales proporcionan las herramientas esenciales y determinantes para responder a los objetivos formulados y llegar a resultados efectivos" (p. 58). Es decir, para responder con eficiencia a las necesidades investigativas, se introdujeron como técnica de recolección el método inductivo, que hizo posible llevar a cabo una valoración de los hechos de forma particular para llegar a la explicación desde una visión general. El autor Bolívar, (2015) tambien expresa que las técnicas de procesamiento de datos en los estudios documentales "son las encargadas de ofrecer al investigador la visión o pasos que deben cumplir durante su ejercicio, cada una de ellas debe estar en correspondencia con el nivel a emplear" (p. 123). Esto indica, que para llevar a cabo el procesamiento de los datos obtenidos una vez aplicadas las técnicas seleccionadas, tales como: fichas de resumen, textual, registros descriptivos entre otros, los mismos se deben ajustar al nivel que ha sido seleccionado.

\section{Resultados}

\section{Anticuerpos monoclonales}

Rituximab, es un anticuerpo monoclonal anti-CD20 dirigido a células $B$, fue el primer anticuerpo monoclonal aprobado por la Administración de Drogas y Alimentos de los Estados Unidos (FDA) para el tratamiento del cáncer en 1997 y desde entonces se ha convertido en el prototipo de anti-CD20. -Anticuerpos monoclonales CD20 y una columna vertebral de los regímenes de tratamiento de malignidad de células B.

Es un anticuerpo de tipo I y, por tanto, exhibe citotoxicidad dependiente del complemento y citotoxicidad dependiente de anticuerpos.

Desde rituximab, se han desarrollado anti- 
cuerpos monoclonales más nuevos dirigidos contra CD20 para su uso en neoplasias malignas de células $B$, incluidos ofatumumab y Obinutuzumab. Ofatumumab es un anticuerpo monoclonal anti-CD20 completamente humanizado de segunda generación que se une a un sitio diferente al de rituximab y también es un anticuerpo de tipo I. Este agente fue aprobado por la FDA para el tratamiento de la leucemia linfocítica crónica (LLC) previamente tratada en 2009 o en combinación con clorambucilo para el tratamiento de la LLC no tratada previamente en 2014 (Hillmen, Robak, \& Janssens, 2015).

El obinutuzumab es otro anticuerpo monoclonal anti-CD20 de segunda generación que es un anticuerpo de tipo II modificado por glicoingeniería, que se diferencia de los demás en que induce la muerte celular directa, junto con una mayor citotoxicidad dependiente de anticuerpos. "Este agente fue aprobado por la FDA en combinación con clorambucilo para el tratamiento de la LLC no tratada previamente en 2013 y en combinación con bendamustina para el tratamiento del linfoma folicular (LF) recidivante / refractario en 2016" (Sehn, Chua, \& Mayer, 2016). Se están realizando estudios con ambos agentes, lo que puede resaltar el mejor papel de estos agentes en el contexto de los regímenes actuales de cáncer de células $B$.

El mieloma múltiple (MM) se había dejado durante mucho tiempo fuera del campo de los anticuerpos monoclonales hasta hace poco, con el aumento en el desarrollo de terapias de anticuerpos monoclonales eficaces basadas en la identificación de antígenos diana. Dos de estos agentes han sido aprobados por la FDA para el tratamiento del mieloma múltiple recidivante / refractario y son muy prometedores.

Daratumumab es un anticuerpo monoclonal anti-CD38 que fue aprobado por la FDA para el tratamiento depacientes que recibieron al menos tres terapias previas, incluido un inhibidor de la proteasoma y un agente inmunomodulador.

CD38 es una glicoproteína transmembrana que se expresa de forma ubicua en las células MM, y se están desarrollando otros anticuerpos monoclonales dirigidos a este antígeno. Daratumumab induce tasas de respuesta global (TRO) del 29 al 36\% en pacientes que han recibido un tratamiento previo intenso como agente único. (Palumbo, Chanan-Khan, \& Weisel, 2016).

Elotuzumab es un anticuerpo monoclonal anti-SLAMF7 (o CS1) que fue aprobado por la FDA en combinación con lenalidomida y dexametasona para el tratamiento de recaídas / refractarias en noviembre de 2015. SLAMF7 "es una glicoproteína que se expresa tanto en células MM como en células asesinas naturales y exhibe efectos antitumorales a través de la citotoxicidad dependiente de anticuerpos" (Ocio, Richardson, \& Rajkumar, 2014), además de potenciar la activación de la citotoxicidad de las células NK a través de la ligadura de SLAMF7, teniendo así dianas duales.

Ha demostrado una "mejora significativa de la supervivencia libre de progresión (SLP) a 1 y 2 años del 68 y el $41 \%$ en comparación con la lenalidomida y la dexametasona en comparación con estos agentes solos, con una TRO del 79\%" (Ocio, Richardson, \& Rajkumar, 2014). Es de destacar que, aparte de las reacciones a la infusión, la adición de estos dos anticuerpos monoclonales a los regímenes de tratamientos actuales del MM no ha provocado toxicidades adicionales.

Existen otros ensayos de combinación en curso que evalúan diferentes regímenes de combinación y entornos clínicos para estos y otros anticuerpos monoclonales en MM. Además de CD38 y SLAMF7, otros objetivos potenciales incluyen CD138, CD56, CD40 y factor de activación de células B (BAFF). Es probable que estos agentes cambien los paradigmas de tratamiento del MM en un futuro próximo. 
VA, G. J.

\section{Conjugados anticuerpo-fármaco}

Los conjugados anticuerpo-fármaco llevan los anticuerpos monoclonales un paso más allá al vincular el anticuerpo dirigido a un agente citotóxico. "El entusiasmo inicial de estos sistemas de administración directa de fármacos aumentó y disminuyó con la aprobación y posterior retirada de gemtuzumab ozogamicina (GO) en 2000 y 2010 respectivamente". Sin embargo, "un metaanálisis reciente de cinco ensayos controlados aleatorios que incluyeron 3325 pacientes con leucemia mieloide aguda (LMA) demostró que el uso de GO mejoró la supervivencia global a 5 años y redujo el riesgo de recaída" (Younes \& Gopal, 2012).

El beneficio absoluto de supervivencia fue especialmente evidente en pacientes con citogenética de riesgo favorable e intermedio. "Estos datos, entre otros, han llevado a reconsiderar la retirada de GO. No obstante, se ha ganado un impulso reciente en las neoplasias hematológicas con el desarrollo de brentuximab, un anticuerpo anti-CD30 ligado a un inhibidor de microtúbulos, MMAE" (Younes \& Gopal, 2012).

Debido a su eficacia en el tratamiento del linfoma de Hodgkin (LH) recidivante / refractario (ya sea después de un trasplante autólogo de células madre o en pacientes que no son candidatos a trasplante) y en el linfoma anaplásico de células grandes sistémico recidivante, que son neoplasias en las que CD30 está altamente expresado, brentuximab recibió la aprobación de la FDA para el tratamiento de estas dos enfermedades en 2011.

Inotuzumab ozogamicina (IO) es otro conjugado anticuerpo-fármaco que se ha probado en neoplasias hematológicas. Este agente se dirige a CD22 y está vinculado al potente antibiótico antitumoral caliqueamicina.

Recientemente se demostró que la 10 ha mejorado significativamente la tasa de remisión completa $(\mathrm{RC})$ del $81 \%$ en compa- ración con la terapia estándar en un ensayo de fase 3 en pacientes con leucemia linfoblástica aguda (LLA) en recaída o refractaria, en una población de pacientes en quienes los resultados no eran muy alentadores. (Porter, Hwang, \& Frey, 2016)

Otro conjugado anticuerpo-fármaco que ha Ilamado la atención recientemente es SGNCD33A, que une un anticuerpo anti-CD33, dirigido a las células $A M L$, con un dímero de pirrolobenzodiazapina. CD33 se expresa en células con linaje mieloide y fue el objetivo del anticuerpo en GO. SGN-CD33A "ha mostrado una tasa de RC del 33\% en la LMA con recaída como monoterapia y tasas de $\mathrm{RC}$ del 60 y $65 \%$ como monoterapia o en combinación con un agente hipometilante en la LMA no apta, respectivamente" (Rogala, Freyer, \& Ontiveros, 2015). Es importante destacar que no ha mostrado ninguna señal de hepatotoxicidad preocupante, que se asoció con GO. Otras dianas para conjugados de anticuerpo-fármaco que están en desarrollo incluyen CD138, CD19 y CD33.

\section{Enganchadores de células $T$ biespecífi- cas}

Otra área interesante de inmunoterapias novedosas son los enganchadores de células $\mathrm{T}$ biespecíficas (BiTE). "Estos agentes tienen dos fragmentos variables de anticuerpos, uno que incluye anti-CD3, que están unidos por un enlazador y, por lo tanto, tienen una especificidad dual para CD3 en las células $\mathrm{T}$, así como un antígeno de superficie tumoral" (Fan, Wang, \& Hao, 2015). Estos agentes unen físicamente las células $\mathrm{T}$ y las células tumorales para catalizar la formación de la sinapsis inmunológica y dar lugar a una respuesta de las células $T$ policlonales y la citotoxicidad de la célula tumoral. Es importante destacar que este proceso es independiente de la expresión de $\mathrm{MHC}$, evitando así uno de los mecanismos de evasión inmunitaria tumoral.

El CD19 es un marcador en la mayoría de las neoplasias malignas de células $B$ y es específico de las células $B$, lo que lo con- 
vierte en un objetivo ideal en la inmunoterapia para estos cánceres, que se destacará en BiTE y en la discusión de las células T del receptor de antígeno quimérico (CAR). El prototipo de los BiTE es blinatumomab, que tiene una especificidad dual para CD3 y CD19, y se ha demostrado que es eficaz en pacientes con LLA de células B en recaída o refractaria.

\section{Células CAR T}

Un área increíblemente prometedora para la inmunoterapia en neoplasias hematológicas ha sido el desarrollo y perfeccionamiento de la terapia con células CAR T, que es un campo que se está moviendo a un ritmo acelerado. Esta terapia implica no solo dirigirse directamente a los antígenos tumorales, sino también el aumento de estos efectores inmunitarios dirigidos.

Las células CAR T son células T autólogas que se diseñan para expresar receptores de antígenos quiméricos contra un antígeno de superficie tumoral específico, por lo que son específicas de antígeno e independientes de HLA y, por lo tanto, son independientes de la expresión de MHC. De acuerdo con Maude \& Teachey, (2015) la anatomía general de los CAR "incluye un fragmento variable monocatenario derivado de un anticuerpo, unido por una bisagra y un dominio transmembrana a un dominio de señalización de células $T$ intracelular con un dominio coestimulador (número y tipo según el CAR específico)"

Esta estrategia ha sido particularmente exitosa en neoplasias hematológicas, dadas varias ventajas en comparación con los tumores sólidos. Malner, (2019) expresa:

Existen antígenos de superficie celular establecidos para apuntar (por ejemplo, CD19 en neoplasias de células B); el muestreo de tumores es sencillo y menos invasivo que en los tumores sólidos; y lo que es más importante, ya existe una localización natural de las células T en las áreas donde se encuentra la malignidad, por ejemplo, sangre, médula ósea, ganglios linfáticos, lo que facilita el camino hacia estos CAR.

El proceso por el cual los pacientes se someten a la terapia con células T con CAR comienza con la recolección de células $T$ autólogas por leucocitaféresis. Luego, el CAR se introduce en las células $T$ a través de uno de los diversos mecanismos, más comúnmente usando vectores virales, y luego, las células se someten a cultivo para su expansión. Por lo general, "los pacientes se someten a quimioterapia de depleción linfoide antes de la infusión de células T con CAR, que puede mejorar la expansión in vivo de las células T mediante la expresión de citocinas homeostáticas, como IL-7 e IL15" (Maude \& Teachey, 2015).

Las primeras terapias exitosas con células T con CAR se han dirigido al CD19 en las neoplasias malignas de las células B. A partir de estas primeras experiencias con las células CAR T, se han aprendido algunas lecciones importantes. Por ejemplo, "es posible que haya remisiones duraderas en el LNH, la LLC y la LLA en recaída / refractaria, y se ha observado la persistencia de linfocitos $T$ con CAR circulantes más de 4 años después de la infusión en pacientes con LLC" (Porter, Hwang, \& Frey, 2016). Además, se han observado tasas notables de RC del 90\% en la LLA en recaída / refractaria, lo que es significativo en comparación con los controles históricos.

Adicionalmente, las células CAR T han sido efectivas en situaciones de enfermedad pre y postrasplante y enfermedad quimio-refractaria, áreas donde las terapias estándar generalmente han fallado. Curiosamente, la enfermedad del sistema nervioso central también se ha eliminado con la terapia de células $T$ con CAR, un área en la que las terapias estándar no penetran.

Una discusión sobre las células CAR T no estaría completa sin destacar el SRC, un proceso inflamatorio relacionado con la proliferación exponencial de células T asociada con una elevación masiva de citoquinas.

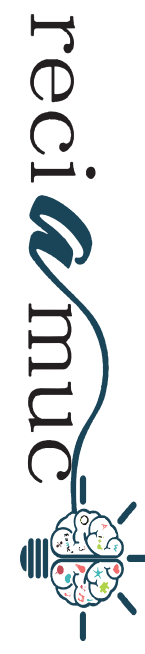


VA, G. J.

"Las lecciones importantes aprendidas de las primeras experiencias con las células CAR T han demostrado la necesidad de esta respuesta y el manejo apropiado del síndrome clínico" (Lee \& Gardner, 2014).

Clínicamente, el SRC se caracteriza por fiebres muy elevadas y síntomas similares a los de la gripe y, cuando es grave, puede provocar fugas vasculares, hipotensión e inestabilidad hemodinámica y fallo multiorgánico. Lee \& Gardner, (2014) expresan:

El manejo del SRC requiere con frecuencia el traslado a la unidad de cuidados intensivos. El único predictor conocido de SRC en este momento es la carga de enfermedad en el momento de la transferencia; sin embargo, también se han demostrado correlaciones con los niveles de proteína $C$ reactiva (PCR) e IL-6 antes del desarrollo del SRC (p. 188).

Otras toxicidades asociadas con la terapia con células CAR T incluyen neurotoxicidad, que puede incluir dolores de cabeza, confusión, alucinaciones, disfasia, ataxia, apraxia, parálisis del nervio facial, temblor, dismetría, encefalopatía global e incluso convulsiones. "La incidencia reportada varía entre 0 y 50\%" (Hillmen, Robak, \& Janssens, 2015). Se trata de una toxicidad aguda que no está relacionada con el $\mathrm{SRC}$, ya que se ha desarrollado después de la aparición y el tratamiento del SRC, y no se previene con un tratamiento previo con tocilizumab. "Sin embargo, la mayoría de los casos se resuelven por sí solos y son autolimitados sin ningún déficit conocido a largo plazo o persistente" (Hillmen, Robak, \& Janssens, 2015).

A pesar de todos estos avances en la terapia con células CAR T, todavía hay preguntas sin respuesta que los investigadores en el campo están tratando de responder rápidamente. Por ejemplo, la construcción óptima de células T con CAR y la ingeniería del injerto aún se desconocen, como el mejor dominio coestimulador de señalización intracelular o la generación de CAR, la pro- porción ideal de células T CD4: CD8 en el injerto infundido, o incluso el predominio del efector. memoria versus células de memoria central e impacto de la presencia de células $T$ reguladoras, entre otros factores.

\section{Bloqueo de puntos de control inmunoló- gico}

Con el entendimiento de que las neoplasias malignas pueden usurpar vías de puntos de control inmunes como la proteína 4 asociada a linfocitos T citotóxicos (CTLA-4) y la muerte programada 1 (PD-1) como un mecanismo de escape inmunológico, "el bloqueo de puntos de control inmunológico se desarrolló, como una estrategia terapéutica que ha demostrado ser eficaz en muchos tumores sólidos, como el melanoma, el cáncer de pulmón no pequeño, el cáncer de células renales y el cáncer urotelial" (Postow, Callahan, \& Wolchok, 2015).

Otra área en la que el bloqueo de los puntos de control inmunológico puede desempeñar un papel interesante en las neoplasias hematológicas es después del trasplante de células madre, dado el entorno inmune único. "Hay pruebas de un aumento de la expresión de PD-1 y PD-L1 en el contexto de LLA en recaída después de blinatumomab y LMA en recaída, lo que sugiere un papel de los inhibidores en estos contextos" (Kohnke, Krupka, \& Tischer, 2015).

Las ventajas de este entorno clínico son que se trata de un estado de enfermedad residual mínimo, la reconstitución inmune conduce a aumentos en los linfocitos que son objetivos de la inhibición de PD-1 y, al menos en el contexto del trasplante alogénico, puede haber un aumento del efecto injerto contra tumor. Sin embargo, una desventaja importante en este contexto es la posibilidad de incitar o exacerbar la enfermedad de injerto contra huésped después del alotrasplante.

\section{Conclusiones}

El pasado y el presente han sido tiempos 
extremadamente emocionantes para la inmunoterapia en neoplasias hematológicas, pero el futuro parece bastante increíble y literalmente la ciencia día a día se mueve hacia él. Claramente varios objetivos ya están en el horizonte con las investigaciones en estas áreas y los beneficios que proporciona. Tomando en consideración, que existe un continuo desarrollo y perfeccionamiento del descubrimiento de antígenos y nuevas inmunoterapias.

Durante el desarrollo del proceso investigativo se observó, la necesidad de ampliar la disponibilidad de inmunoterapias novedosas más allá de los centros altamente especializados. Además del desarrollo de experiencias en el manejo de complicaciones únicas relacionadas con inmunoterapias novedosas y estableciendo pautas de práctica, que serán esenciales con la ampliación del uso.

Sin embargo, es importante perfeccionar los criterios de valoración clínicos apropiados y las evaluaciones de respuesta al estudiar estos nuevos agentes. La combinación de inmunoterapias es un área de investigación interesante que probablemente mejorará aún más la capacidad de aprovechar el sistema inmunológico para combatir las neoplasias malignas hematológicas.

Es evidente, que existe una pequeña posibilidad de que nuevas terapias puedan incluso reemplazar al HCT en el futuro como una opción curativa para algunas neoplasias malignas hematológicas, pero por ahora, el HCT sigue siendo una opción terapéutica esencial, y la combinación de HCT con nuevas terapias es un paso claro en el futuro. Se espera que más temprano que tarde los investigadores logren una sinergia en este tipo tratamientos donde lo que se ha descrito como el "arma más contundente del quimio terapeuta" se pueda combinar con inmunoterapias novedosas para lograr lo que es verdaderamente la "bala mágica" para los pacientes con neoplasias hematológicas.

\section{Bibliografía}

Caballeros, M., López, L., \& Cabrero, M. (2012). Efecto de injerto contra tumor. Rev Hematol Mex , 13 ((3)), 89-93.

Chang, Y., Xu, L., \& Wang, Y. (2016). Controlled, randomized, open-label trial of risk-stratified corticosteroid prevention of acute graft-versus-host disease after haploidentical transplantation. J Clin Oncol , 1855-63.

Fan, G., Wang, Z., \& Hao, M. (2015). Bispecific antibodies and their applications. J Hematol Oncol, 8:130.

Hillmen, P., Robak, T., \& Janssens, A. (2015). Chlorambucil plus ofatumumab versus chlorambucil alone in previously untreated patients with chronic lymphocytic leukaemia (COMPLEMENT 1): a randomised, multicentre, open-label phase 3 trial. Lancet, 1873-83.

Kohnke, T., Krupka, C., \& Tischer, J. (2015). Increase of PD-L1 expressing B-precursor ALL cells in a patient resistant to the CD19/CD3-bispecific T cell engager antibody blinatumomab. J Hematol Oncol , 8:111.

Lee, D., \& Gardner, R. (2014). Current concepts in the diagnosis and management of cytokine release syndrome. Blood, 188-95.

Malner, A. (2019, 09 02). Terapia CAR-T, revolución en el abordaje del cáncer. Retrieved 11 18, 2020 from Rafer.es: https://www.rafer.es/innovacion-laboratorio-clinico/terapia-car-t/

Maude, S., \& Teachey, D. (2015). CD19-targeted chimeric antigen receptor T-cell therapy for acute lymphoblastic leukemia. Blood , 4017-23.

Mukherjee, S. (2010). The emperor of all maladies. New York: Scribner.

Ocio, E., Richardson, P., \& Rajkumar, S. (2014). New drugs and novel mechanisms of action in multiple myeloma in 2013: a report from the International Myeloma Working Group (IMWG). Leukimia , 542549.

Palumbo, A., Chanan-Khan, A., \& Weisel, K. (2016). Daratumumab, bortezomib, and dexamethasone for multiple myeloma. N Engl J Med , 754-66.

Porter, D., Hwang, W., \& Frey, N. (2016). Chimeric antigen receptor $\mathrm{T}$ cells persist and induce sustained remissions in relapsed refractory chronic lymphocytic leukemia. Sci Transl Med, 24-65.

Postow, M., Callahan, M., \& Wolchok, J. (2015). Immune checkpoint blockade in cancer therapy. $J$

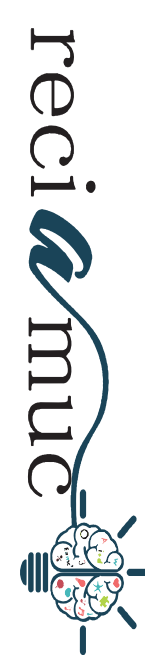


VA, G. J.

Clin Oncol , 1974-82.

Rogala, B., Freyer, C., \& Ontiveros, E. (2015). Blinatumomab: enlisting serial killer T-cells in the war against hematologic malignancies. Expert Opin Biol Ther , 895-908.

Sehn, L., Chua, N., \& Mayer, J. (2016). Obinutuzumab plus bendamustine versus bendamustine monotherapy in patients with rituximab-refractory indolent non-Hodgkin lymphoma (GADOLIN): a randomised, controlled, open-label, multicentre, phase 3 trial. . 2016;17:. Lancet Oncol , 1081-93.
Whiteside, T. (1998). Immune cells in the tumor microenvironment. Mechanisms responsible for functional and signaling defects. Adv Exp Med Biol , $167-71$.

Younes, A., \& Gopal, A. (2012). Results of a pivotal phase II study of brentuximab vedotin for patients with relapsed or refractory Hodgkin's lymphoma. J Clin Oncol , 2183-9.

\section{CITAR ESTE ARTICULO:}

Carvajal Correa, A. J., Gavilema Tipantuña, D. I., Pinos Ramírez, Ángel D., \&

Curicho Córdova, G. J. (2021). Inmunoterapia en hemopatías malignas. RE-

CIAMUC, 4(4 (esp), 102-112. https://doi.org/10.26820/reciamuc/4.(4).diciembre.2020.102-112 